\title{
The FDA: A dromedary tale
}

There's a story about a bridegroom who whisks his bride into the desert on a camel. The camel stumbles, and the man dismounts and smacks the camel around the head and says, "that's one." They go on at breakneck speed, and the camel stumbles again. The man dismounts and kicks and beats the camel and says, "that's two." They go on further still into the desert and the camel trips yet another time. The man gets down and shoots the camel between the eyes. "That's three," he says. "My God, husband," cries the bride, "what have you done?" He turns to her and says "that's one."

It's a story that certain industry commentators, biotechnology companies, and their umbrella organizations would do well to keep in mind. Instead of sniping at the FDA, they should recognize the accomplishments of the past six years and cooperate with the new commissioner to refine the approval process for their drugs. While biotechnology may not have had a close personal friend in soon-to-be former Commissioner David Kessler, he was no enemy either.

The newly appointed Kessler made some costly errors with respect to food biotechnology (see p. 3). But when it came to drug development (see p. 9), he made significant progress in bringing down approval times for new chemical entities and, when political pressures (and benefits) were greatest, as was the case with HIV protease inhibitors, orchestrated quite a remarkable series of accelerated review processes.

Even granting that Kessler did what he could, given the time and the resources he had to work with, the real problems faced by the FDA cannot be solved by any single individual, however good and noble and enthusiastic and intelligent that person is.

A long and complex agenda of issues faces the new commissioner: New chemical entity approvals need to be even further streamlined and the issue of privatizing review of new drug applications considered, supplementary indication and off-label use issues need to be addressed, as do a number of marketing/labeling logjams. It is clear that no single individual can exact the kind of changes that need to take place at FDA. But with cooperation from the pharmaceutical and biotechnology industries, it is could turn out to be less of a Sisyphean task.

Biotechnology, even more than the pharmaceutical industry, stands to gain from FDA reform of the kind begun during the Kessler years. The parties involved need to continue to work to change the relationship between submitting companies and the FDA from adversarial to cooperative. It is in the best interests of the FDA to have the best products approved rapidly, and its is in the best interests of companies to have a rigorous regulatory system working on their behalf to protect them from products disasters, market withdrawals, and the litigious wrath of formularies, managed health-care organizations, and insurance companies, all of whom are putting increasing demands of their own on drug development-not only do they want to know it if will work, they want to know if it's worth paying for. By actively helping the new commissioner chart the next course of biopharmaceutical development, biotechnology could significantly advance its own cause.

Some say that FDA should be charged with a mission statement like those of the US Department of Agriculture or the Federal Aviation Administration---their mandates are to regulate and to promote their respective industries. This is the kind of thinking that makes consumers, Congress, and the press assume that proindustry must auto- matically mean anticomsumer. The best proindustry FDA one could imagine would be one that made approval of safe, efficacious drugs rapid and routine. We encourage biotechnology companies and their representatives to work with the new commissioner to get us where we want to go. It's tough to get across the desert alone and on foot.

\section{Transgenic bagels and neurotic genes}

California-based artist Sonya Rapoport has found the perfect vector for the genetic engineering of complex traits-the bagel, a classic New York food staple-and you can see her work in The Digital Salon96 exhibit (http://www.sva.edu/salon/salon96/net-works/ rapoport). State-of-the-art recombinant bagel technology allows you to genetically alter your persona on demand. The Rapoport "theory" of complex traits is built around the hypothesis that Noah's ark was the first gene pool, and that each animal residing on the ark had a trait gene in its "Noahsomal" DNA that can be transferred to humans via genetic manipulation and the use of bagel "plasmid vectors." These traits are named after biblical characters-thus, if you want to add prudence to your character, you can select the "Jacob trait" and insert it into the bagel plasmid of your choice.

Not as parodic as it might appear, if you believe recent press coverage of the discovery of a "neurosis gene" in late November (Science 274k1527-1531, 1996). According to many of these reports, complex behavioral traits can now, it seems, be explained in terms of the inheritance of a single gene. Such reports are not just the result of media oversimplification and distortion. Some overenthusiastic researchers are helping to spread the smear.

We would all benefit from the consumption of some Jacob trait vectors when it comes to descriptions of genetic complexity. As Nature Biotechnology was going to press, it was announced that another group of researchers had reported the discovery of a gene in the male fruit fly, fruitless, that seems to govern the fly's entire sex life--from choosing a mate to the particular form of the cha-cha he uses to attract her (Cell 87:1079-1089, 1996). When asked whether comparable genes will be found in humans, for sex or any other complex behaviors, one of the researchers involved was quoted as saying "that's a perfectly reasonable possibility."

Pass the cream cheese.

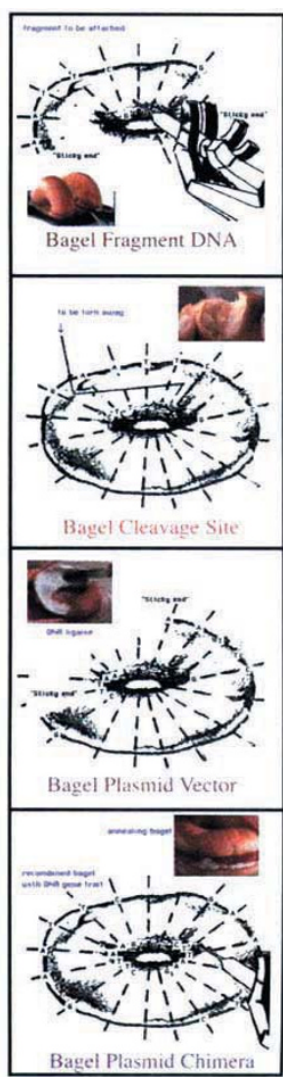

